\title{
Home is where our journey begins -2 years' impact of an orthopaedic early supportive discharge (OSD) team in our hip fracture service
}

\author{
Authors: Radcliffe Lisk, Hazel Watters, Michal Krasuski and Keefai Yeong
}

\section{Aims}

Patients with a fractured neck of femur (NOF) spend a significant amount of time in hospitals, recuperating after the acute event and undergoing rehabilitation. This model of care consumes a lot of resources, increases the risk of institutionalisation and may lead to hospital-related harm. NICE guidelines suggest considering early supported discharge as part of the hip fracture programme.

\section{Methods}

The team was set up using a $£ 90,000$ start-up from our trust's innovation fund and improving care using PDSA cycles below:

$>$ Three test patients taken out by ward physiotherapist

$>$ The team (physiotherapist, nurse 0.6WTE, OT 0.7WTE, two therapy assistants) was operational from 1 March 2014, with the capacity to support eight patients

$>$ Engagement meetings with patients, GPs and community partners

$>$ To reduce risk of readmission, patients were given fast-track access to fracture and geriatric clinics

> Capacity increased to 12 patients through efficiency and introduction of cross-specialty working

$>$ Addition of a nurse and therapy assistant - coupled with further improvement in processes - increased capacity to 20 patients.

\section{Results}

As the OSD team also take a significant number of other orthopaedic patients, this has allowed us to close 22 of our trust's rehabilitation beds in July 2015. 3,671 bed days were saved, with overall cost savings of $£ 810,136$ ( $£ 275$ per bed day) for NOF patients. In addition, the OSD team took out 73 nonNOF patients in Mar-Feb 2015, increasing to 175 non-NOF patients in Mar-Feb 2016. Of the 263 patients who responded to the friends and family questionnaire, $99.6 \%$ provided positive feedback (extremely likely / likely to recommend the service). As one patient said, 'I wish every hospital in the land could take up this scheme'.

\section{Conclusions}

OSD should be part of all hip fracture services, as it is very costeffective, increases home-to-home discharge and reduces LOS, which leads to significant savings.

\section{Conflict of interest statement}

None.

\begin{tabular}{|c|c|c|c|c|c|c|c|}
\hline & $\begin{array}{l}\text { Mar-Feb } \\
2014\end{array}$ & $\begin{array}{l}\text { Mar-Feb } \\
2015\end{array}$ & $\begin{array}{l}\text { Mar-Feb } \\
2016\end{array}$ & & $\begin{array}{l}\text { Mar-Feb } \\
2014\end{array}$ & $\begin{array}{l}\text { Mar-Feb } \\
2015\end{array}$ & $\begin{array}{l}\text { Mar-Feb } \\
2016\end{array}$ \\
\hline No of NOF patients & 393 & 423 & 395 & LOS days & 21.5 & 18.2 & 14.03 \\
\hline $\begin{array}{l}\text { NOF patients discharged } \\
\text { with OSD }\end{array}$ & & 105 & 106 & $\begin{array}{l}\text { \% sent to rehabilitation } \\
\text { (part of trust) }\end{array}$ & $44.2 \%$ & $23.6 \%$ & $8.60 \%$ \\
\hline NOF bed days & 8,456 & 7,699 & 5,542 & Readmissions & $7.89 \%$ & $7.57 \%$ & $8.72 \%$ \\
\hline OSD costs & & $£ 175,211$ & $£ 209,955$ & Home to home ( 30 days) & $53.9 \%$ & $61.2 \%$ & $66.3 \%$ \\
\hline Cost savings & & $£ 208,662$ & $£ 601,474$ & Mortality & $4.83 \%$ & $4.96 \%$ & $5.10 \%$ \\
\hline
\end{tabular}

